\title{
Mouse Models of Heart Failure with Preserved or Reduced Ejection Fraction
}

\author{
Natalie A. Noll, ${ }^{*}$ Hind Lal, ${ }^{\dagger}$ and W. David Merryman*
}

From the Department of Biomedical Engineering, * Vanderbilt University, Nashville, Tennessee; and the Department of Medicine, Cardiovascular Disease, ${ }^{\dagger}$ University of Alabama at Birmingham, Birmingham, Alabama

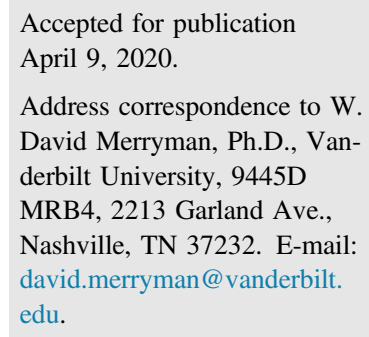

Address correspondence to W. David Merryman, Ph.D., Vanderbilt University, 9445D MRB4, 2213 Garland Ave. Nashville, TN 37232. E-mail: david.merryman@vanderbilt. edu.

\begin{abstract}
Heart failure (HF) is a chronic, complex condition with increasing incidence worldwide, necessitating the development of novel therapeutic strategies. This has led to the current clinical strategies, which only treat symptoms of HF without addressing the underlying causes. Multiple animal models have been developed in an attempt to recreate the chronic HF phenotype that arises following a variety of myocardial injuries. Although significant strides have been made in HF research, an understanding of more specific mechanisms will require distinguishing models that resemble $\mathrm{HF}$ with preserved ejection fraction (HFpEF) from those with reduced ejection fraction (HFrEF). Therefore, current mouse models of $\mathrm{HF}$ need to be re-assessed to determine which of them most closely recapitulate the specific etiology of $\mathrm{HF}$ being studied. This will allow for the development of therapies targeted specifically at HFpEF or HFrEF. This review will summarize the commonly used mouse models of HF and discuss which aspect of human HF each model replicates, focusing on whether HFpEF or HFrEF is induced, to allow better investigation into pathophysiological mechanisms and treatment strategies. (Am J Pathol 2020, 190: 1596-1608; https://doi.org/10.1016/j.ajpath.2020.04.006)
\end{abstract}

Heart failure (HF) is a leading cause of death worldwide. Approximately 6.5 million Americans are living with $\mathrm{HF}$, with an incidence of 10 in 1000 individuals older than 65 years. ${ }^{1}$ Recently, morbidity attributed to HF has decreased to one in nine deaths because of improvements in established treatment strategies focused on conditions preceding and leading to $\mathrm{HF}$, including hypertension, myocardial infarction (MI), and atherosclerosis. ${ }^{2}$ However, mortality associated with HF is high, with $50 \%$ of patients diagnosed with HF dying within 5 years of diagnosis. ${ }^{3}$ Current predictions show that by 2030, 8 million US adults will be diagnosed with $\mathrm{HF}^{3}$ Therefore, there is a need to identify risk factors and develop new therapeutic strategies for $\mathrm{HF}$ patients.

Two-thirds of all HF cases can be attributed to one of four underlying conditions: ischemic heart disease, chronic obstructive pulmonary disease, hypertensive heart disease, or rheumatic heart disease. ${ }^{4}$ During these pathologic conditions, systemic inflammation, hypoxic environment, cardiomyocyte death, mechanical stress, and other profibrotic cytokines lead to the migration and proliferation of cardiac fibroblasts to the site of injury and their activation into myofibroblasts. Myofibroblasts develop stress fibers, are more contractile, and secrete profibrotic signaling factors, such as transforming growth factor- $\beta$, tumor necrosis factor$\alpha$, and angiotensin II (Ang II), which can induce and modify cardiomyocyte hypertrophy (Figure 1). ${ }^{5}$ Myofibroblasts are also the major cell type responsible for laying down the extracellular matrix, resulting in interstitial and perivascular fibrosis that stiffens the myocardium, and can also lead to collagenous scar formation during acute injury., ${ }^{5,6}$ This fibrosis exacerbates any myocardial stiffening and diastolic dysfunction that may have arisen before fibroblast activation due to energy metabolism issues and systemic inflammation. ${ }^{7,8}$ These changes can lead to a hypertrophic response of the left ventricle (LV), interfering with the LV's ability to relax, resulting in diastolic dysfunction (Figure 2).

Supported by NIH grants F31-HL149168 (N.A.N.), R01-HL143074 (H.L.), R01-HL133290 (H.L.), and R35-HL135790 (W.D.M.); and Foundation Leducq (W.D.M.).

Disclosures: None declared. 
Additional insults, such as chronic deterioration or ischemic injury leading to cardiomyocyte death, result in decreased contractile force and wall thickness, leading to systolic dysfunction where the LV has impaired filling (Figure 2). ${ }^{9}$ Increased myocardial stiffness and diminished LV contractility, the results of pathologic remodeling, are the primary hallmarks of HF.

The American Heart Association defines HF as a complex clinical syndrome that results from any structural or functional impairment of ventricular filling or ejection of blood (https://www.heart.org/en/health-topics/heart-failure/whatis-heart-failure, last accessed October 30, 2019). Left-sided $\mathrm{HF}$, which is often a precursor for right-sided HF, is associated with an increased risk of sudden death. ${ }^{10}$ Left-sided $\mathrm{HF}$ is subdivided on the basis of LV ejection fraction (EF): HF with preserved EF (HFpEF; LV EF $\geq 50 \%$ ), HF with midrange $\mathrm{EF}$ (LV EF $40 \%$ to $49 \%$ ), and $\mathrm{HF}$ with reduced EF (HFrEF: LV EF < 40\%). In the United States, half of all HF patients are diagnosed with HFpEF.

HFpEF is clinically defined as HF with normal EF and diastolic dysfunction: the inability of the ventricles to relax properly. ${ }^{11} \mathrm{HFpEF}$ is usually a result of chronic diseases, such as hypertension, diabetes mellitus, atrial fibrillation, aging, obesity, or renal dysfunction (Figure 2). ${ }^{12}$ These chronic diseases gradually diminish the normal relaxation ability of the LV as the ventricular wall becomes stiffer from increasing interstitial fibrosis. As a result, the heart can no longer fill properly with blood during the resting period between each beat, which eventually leads to diastolic failure. HFpEF occurs more often in women $(79 \%$ versus $49 \%$ of all heart failure) and is more prominent in older populations. ${ }^{11} \mathrm{HFpEF}$ manifests clinically as exercise intolerance, dyspnea, edema, pulmonary hypertension $(\mathrm{PH})$, and pulmonary edema, all of which are symptoms associated with cardiac hypertrophy, increased fibrosis, and decreased capillary content.

In contrast with the reduced relaxation capacity of HFpEF, HFrEF occurs when the ventricle loses its ability to contract normally. A wide range of cardiac conditions can cause HFrEF, including coronary artery disease, MI, and cardiomyopathies (Figure 2). ${ }^{12}$ These diseases result in apoptosis of cardiomyocytes and increased wall stress, diminishing the ability of cardiomyocytes to contract with enough force to push the blood into the systemic circulation, which eventually leads to systolic failure. Patients with HFrEF have higher levels of circulating brain natriuretic peptide, a common biomarker for HF, and a higher mortality rate than those with HFpEF. ${ }^{13}$

Mouse models of HF have been used to improve our understanding of the various aspects and etiologies of $\mathrm{HF}$, toward the ultimate goal of developing novel treatment strategies. Mice are the most commonly used animal models in HF research, as they share most of their genes with humans and approximately $85 \%$ of the proteincoding regions are identical to the human genome. ${ }^{14}$ In addition, mice provide unique experimental advantages, such as the ability to impose genetic alterations, short breeding cycles, and relatively low housing costs. Numerous murine models of HF have been developed through a combination of genetic modifications, administration of pharmacologic compounds, and/or surgical approaches to recapitulate human disease. ${ }^{14,15}$ Mouse models allow for the study of specific risk factors of and treatment strategies for HF without some of the confounding effects of comorbidities seen in other animal models. Over the past decade, a large increase in mouse models of HF has increased our knowledge of both

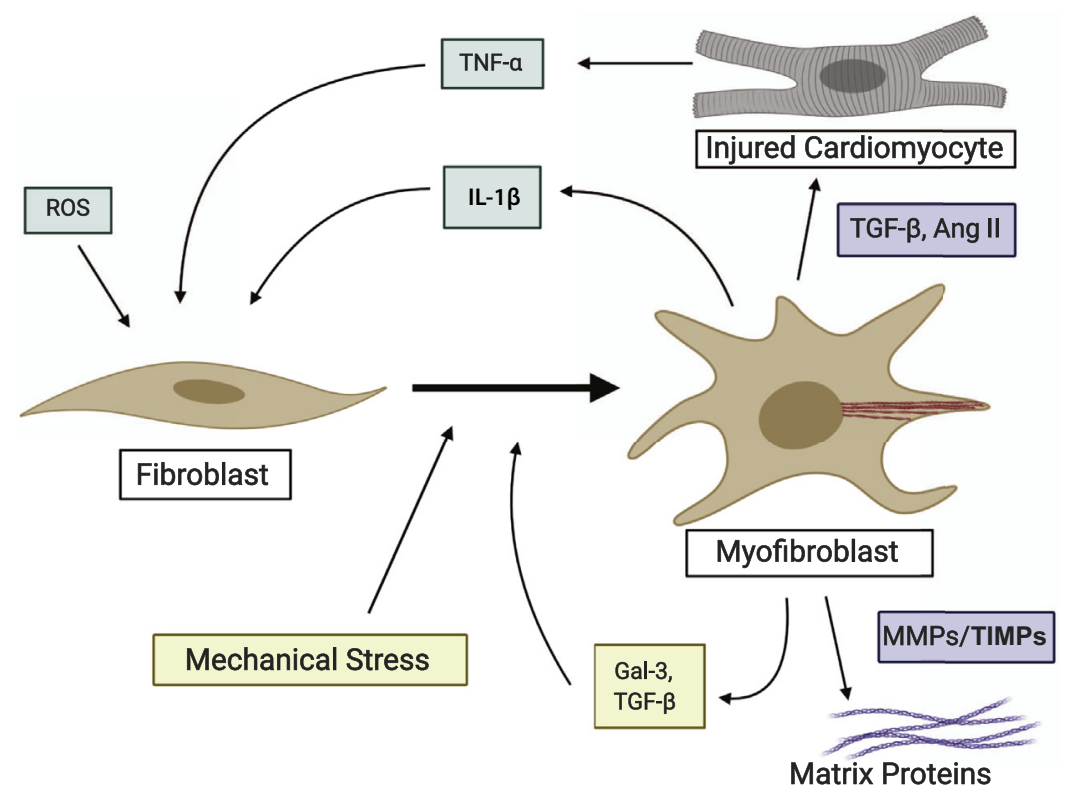

Figure 1 Fibroblast to myofibroblast transition in the heart in response to cardiomyocyte injury, proinflammatory cytokines, and systemic inflammation through reactive oxygen species (ROS). Created with BioRender.com. Ang II, angiotensin II; Gal-3, galectin-3; MMP, matrix metalloprotinase; TGF- $\beta$, transforming growth factor- $\beta$; TIMP, tissue inhibitor of metalloprotinase; TNF- $\alpha$, tumor necrosis factor- $\alpha$. 
HFpEF and HFrEF, many of which are highlighted in this article and summarized in Table $1^{16-67}$

\section{Mouse Models of HFpEF}

This section discusses mouse models of HFpEF. These models strive to recapitulate the chronic disease progression and risk factors associated with the development of HFpEF, including hypertension, obesity, diabetes, and aging. Some of these models, if permitted to run long enough, may also lead to the development of HFrEF.

\section{Hypertension}

Hypertension is one of the main underlying conditions that leads to HFpEF in humans. ${ }^{4,68}$ Hypertension, which causes broad changes in inflammation and metabolism, can cause myocardial stiffness and diastolic dysfunction. ${ }^{7}$ This is additionally exacerbated when hypertension results in increased pressure in the $\mathrm{LV}$, resulting in the expansion of fibroblasts, hypertrophy of vascular smooth muscle cells, and pathologic deposition of interstitial collagen. This leads to increased myocardial wall stress, which causes LV hypertrophy in an attempt to compensate for the increased pressure. ${ }^{69}$ The most commonly used mouse model to study hypertension-induced $\mathrm{HFpEF}$ is the administration of deoxycorticosterone acetate (DOCA) while providing highsalt $(1 \% \mathrm{NaCl})$ drinking water. This model causes increased sodium and water reabsorption in the kidneys, leading to high blood pressure through a decrease in the renin/aldosterone ratio. This model has also been shown to be mouse strain dependent, as $\mathrm{C} 57 \mathrm{BL} / 6 \mathrm{~J}$ mice are less susceptible to renal damage and hypertension than the $129 / \mathrm{Sv}$ strain. ${ }^{16}$ In addition, renal impairment is more severe in males than in females. ${ }^{17}$ The DOCA model results in cardiac hypertrophy, ventricular fibrosis, up-regulation of the hypertrophy markers atrial natriuretic peptide and brain natriuretic peptide, and infiltration of inflammatory cells into the cardiac tissue. $^{17}$

Ang II administration has also been used to induce hypertension and chronic kidney disease (CKD) in mice. Sustained elevation of Ang II levels in the circulation results in Ang II-mediated vasoconstriction, hypertension, aldosterone secretion, transforming growth factor- $\beta$-mediated fibrosis, and inflammation-all of which contribute to the development of cardiac hypertrophy. This model has contributed to many cardiovascular discoveries, including that sildenafil, an inhibitor of cyclic GMP-specific phosphodiesterase type-5A (PDE5A), improves LV performance, reduces adverse remodeling, and diminishes infiltration of inflammatory cells during Ang II-induced HFpEF. ${ }^{18}$ In addition, the Ang II model has been combined with the DOCA salt and uninephrectomized models in an attempt to overcome the resistance of $\mathrm{C} 57 \mathrm{BL} / 6 \mathrm{~J}$ mice to CKD and hypertension development. ${ }^{19,20}$

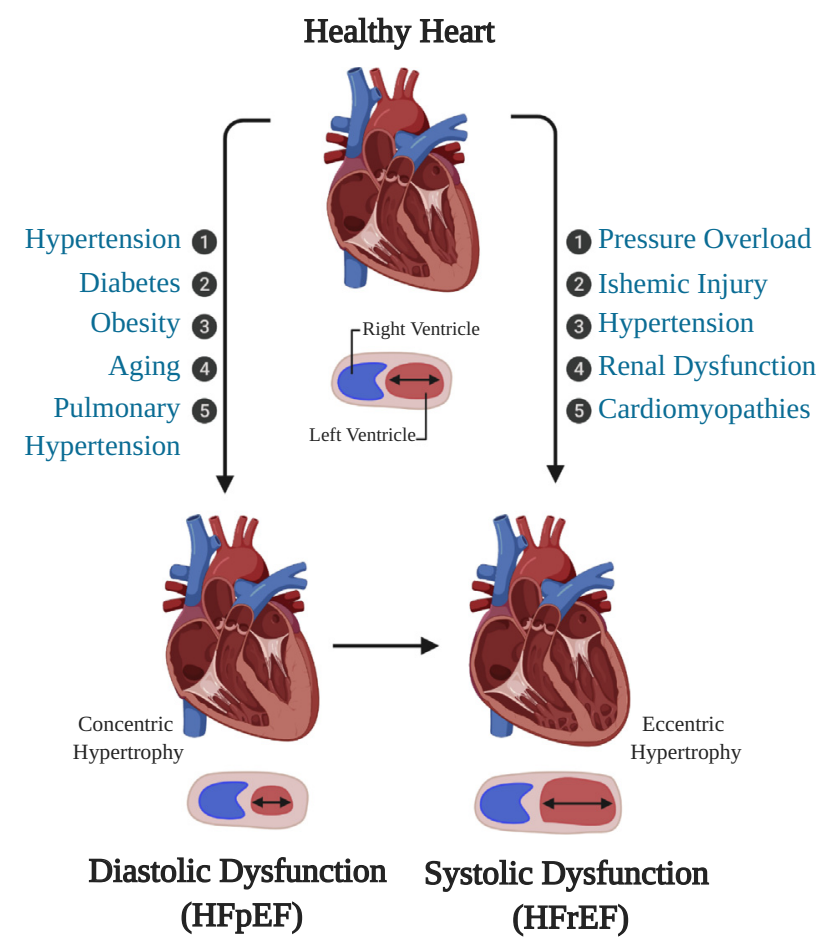

Figure 2 Disease states and their resulting left ventricular remodeling leading to the development of heart failure with preserved ejection fraction (HFpEF) and heart failure with reduced ejection fraction (HFrEF). Created with BioRender.com.

\section{Pulmonary Hypertension}

Diastolic dysfunction, as experienced in HFpEF, is the most frequent cause of pulmonary hypertension $(\mathrm{PH}) .^{70} \mathrm{PH}$ is commonly found in deteriorating $\mathrm{HFpEF}$, and is therefore closely associated with worse outcomes and mortality in patients with HFpEF. ${ }^{71}$ During HFpEF, chronically elevated filling pressure in the LV causes backward pressure in the pulmonary arteries, resulting in vascular remodeling and increased pulmonary arterial pressure, pulmonary vascular resistance, and right ventricular hypertrophy that are associated with $\mathrm{PH}^{72} \mathrm{PH}$ exacerbates the LV diastolic dysfunction that is already occurring in the heart. ${ }^{73}$ As a result, mouse models of $\mathrm{PH}$ were developed to study how $\mathrm{PH}$ leads to increased diastolic dysfunction. AKR/J, NON/ shiLtJ, and WSB/EiJ mice, when placed on a high-fat diet for 20 weeks, develop elevated right ventricular systolic pressure and LV end-diastolic pressure while having a preserved EF. ${ }^{21}$ These findings illustrate that these mice develop biventricular hypertrophy, $\mathrm{HFpEF}$, and $\mathrm{PH}$.

\section{Type 2 Diabetes}

Cardiovascular complications are the leading cause of diabetes-related morbidity and mortality. ${ }^{74}$ Diabetes mellitus, or type 2 diabetes (T2D), is non-insulin dependent and results from a combination of insulin resistance and $\beta$-cell 
secretory defects. ${ }^{75}$ Complications associated with T2D include increased coronary heart disease and accelerated atherosclerosis due to associated risk factors of hypertension, obesity, and dyslipidemia. ${ }^{76} \mathrm{Db} / \mathrm{db}$ and ob/ob mice are the most commonly used T2D that are based on leptin receptor deficiency or lack of functional leptin, respectively. ${ }^{22}$ In both mouse models, circulating leptin is taken up in the hypothalamus, causing an increase in appetite and body weight, and decreased energy expenditure. This results in both models having severe, early-onset obesity at 4 weeks of age and the development of hyperinsulinemia and T2D by 15 weeks. ${ }^{77}$ Cardiac hypertrophy, increased LV mass, and diastolic dysfunction occur in these mice as myocardial oxygen consumption is increased, resulting in decreased cardiac efficiency. ${ }^{22-24} \mathrm{Ob} / \mathrm{ob}$ mice experience contractile dysfunction; however, $\mathrm{db} / \mathrm{db}$ cardiomyopathies are more pronounced. ${ }^{25}$ The major disadvantage of the $\mathrm{db} / \mathrm{db}$ and $\mathrm{ob} /$ ob mouse models is that although there is a robust phenotype of T2D, there are potentially confounding adverse effects from altered leptin signaling. In $\mathrm{db} / \mathrm{db}$ mice, there is no altered tyrosine kinase signaling changes in cardiomyocytes, a variation from decreased signaling seen in human muscle tissue. ${ }^{26}$ In ob/ob mice, the innate and acquired immune response is repressed, potentially resulting in an altered response to acute and chronic injury to the heart. ${ }^{78}$

\section{Type 1 Diabetes}

Type 1 diabetes (T1D) is defined by the National Institute of Diabetes and Digestive and Kidney Diseases as an autoimmune disease in which the immune system attacks and destroys insulin-producing pancreatic $\beta$-cells, resulting in an absolute insulin deficiency (https://www.niddk.nih.gov/ health-information/diabetes/overview/what-is-diabetes/ type-1-diabetes, last accessed November 15, 2019). The autosomal dominant mutant INS gene is one known human genetic cause of T1D and serves as a reproducible model of T1D in mice. ${ }^{79}$ The Akita mouse (Ins $2^{\text {Akita+/- }}$ ) is heterozygous for the Ins 2 gene mutation, wherein all males develop T1D after weaning age. At 5 to 6 weeks of age, the Akita mice develop hyperglycemia (which is similar to humans who develop T1D between 15 and 25 years of age). ${ }^{27}$ At 12 weeks, these mice have an increase in the circulating HF markers atrial natriuretic peptide and brain natriuretic peptide with diastolic dysfunction and a decrease in the radial strain occurring between 3 and 6 months. ${ }^{27,28}$

To look at the acute onset of T1D in mice, streptozotocin (STZ), which directly kills pancreatic $\beta$-cells, is administered, inducing chronic T1D. High doses of STZ can cause toxicity outside of the pancreas, so a low continuous dose of STZ is recommended. The STZ mouse model results in hyperglycemia 7 to 14 days after the first injection. ${ }^{29}$ STZ induces early diastolic and vascular dysfunction, which is progressively exacerbated by the development of diabetes, leading to systolic dysfunction and HFpEF, accompanied by abnormal patterns of mitral valve inflow and pulmonary venous flow. ${ }^{30,31}$ Although the STZ model of T1D produces a robust imitation of the disease, it does not capture the autoimmune aspect of the development of T1D in humans.

Acute onset of T1D can also be studied without the use of toxins by using OVE26 mice. OVE26 mice overexpress calmodulin in pancreatic $\beta$-cells, resulting in mice with diabetic nephropathy and severe early onset of T1D during the first week of life. OVE26 mice can live for 1 year with no insulin treatment and will maintain near-normal body weight. $^{32}$ These mice spontaneously develop diastolic dysfunction with an increase in end-systolic interventricular septum thickness and end-systolic left ventricular posterior wall thickness. When treated with Ang II, OVE26 mice have exacerbated cardiac hypertrophy, with an increase in LV mass and atrial natriuretic peptide expression. ${ }^{33}$

\section{Obesity}

Obesity is a complex chronic disease resulting from the accumulation of several physiological changes over a long period of time and is associated with many other risk factors in the development of HF (eg, hypertension, diabetes, and psychosocial stress). In the laboratory, dietinduced obesity in mice has been developed as the standard practice to probe the pathologic contributions of an imbalance of food intake, basal metabolism, and energy expenditure. ${ }^{34}$ C57BL/6J mice on a high-fat diet closely parallel patterns of progression and metabolic irregularities found in human obesity. After 2 weeks, C57BL/6J mice have decreased rates of glucose oxidation and glycolysis, which further develops into obesity and T2D. ${ }^{35}$ At 20 weeks, a $20 \%$ to $30 \%$ increase in body weight occurs alongside cardiac dysfunction, elevated filling pressures, myocardial fibrosis, and exercise intolerance. ${ }^{36}$ This model was used to discover the importance of Akt, a mammalian target of rapamycin signaling in obesity. ${ }^{37}$ Physiosocial stress is recognized as an independent risk factor for cardiovascular disease, and when it is added to a high-fat diet model of obesity, cardiac dysfunction will occur. ${ }^{38}$ This model results in prominent interstitial fibrosis, apoptosis of cardiomyocytes, remodeling of the larger coronary branches, and augmented oxidative stress in the $\mathrm{LV} .{ }^{38}$

\section{Aging}

HF is disproportionately distributed among elderly individuals, as over half of all patients hospitalized with $\mathrm{HF}$ are older than 75 years, with $50 \%$ presenting with diastolic dysfunction. ${ }^{80}$ The senescence-accelerated prone mouse, derived from inbreeding $\mathrm{AKR} / \mathrm{J}$ mice, recapitulates many common geriatric disorders evident in elderly human populations. ${ }^{39}$ The senescence-accelerated prone mouse model is composed of both a senescence-prone and a senescenceresistant control strain. The senescence-accelerated prone mouse strains are the best-studied strains regarding HFpEF, 
Noll et al

Table 1 Mouse Models Used to Induce HFpEF or HFrEF

\begin{tabular}{|c|c|c|c|c|c|}
\hline $\begin{array}{l}\text { Type of } \\
\text { HF model }\end{array}$ & Model & Stimuli & Advantages & Disadvantages & $\begin{array}{l}\text { Selected } \\
\text { references }\end{array}$ \\
\hline \multirow[t]{12}{*}{ HFpEF } & \multirow[t]{3}{*}{ Hypertension } & DOCA & $\begin{array}{l}\text { Reliable model of } \\
\text { hypertension }\end{array}$ & $\begin{array}{l}\text { Non-specific adverse } \\
\text { effects, such as the } \\
\text { development of } \\
\text { chronic kidney } \\
\text { disease }\end{array}$ & 16,17 \\
\hline & & Ang II & $\begin{array}{l}\text { Reliable model of } \\
\text { hypertension }\end{array}$ & $\begin{array}{l}\text { Non-specific adverse } \\
\text { effects, such as the } \\
\text { development of } \\
\text { chronic kidney } \\
\text { disease }\end{array}$ & 18 \\
\hline & & $\begin{array}{l}\text { DOCA + Ang } \\
\text { II + uninephrectomy }\end{array}$ & $\begin{array}{l}\text { Allows for } \\
\text { hypertension } \\
\text { development in } \\
\text { C57/Bl/6 mice }\end{array}$ & & 19,20 \\
\hline & $\begin{array}{l}\text { Pulmonary } \\
\text { hypertension }\end{array}$ & High-fat diet & $\begin{array}{l}\text { Mimics right } \\
\text { ventricular } \mathrm{HF}\end{array}$ & $\begin{array}{l}\text { Models an } \\
\text { exasperator of } \\
\text { HFpEF and not an } \\
\text { initial stimulus of } \\
\text { disease }\end{array}$ & 21 \\
\hline & \multirow[t]{2}{*}{ Type 2 diabeties } & $\mathrm{db} / \mathrm{db}$ mouse & $\begin{array}{l}\text { Reliable model of } \\
\text { T2D }\end{array}$ & $\begin{array}{l}\text { Time-dependent } \\
\text { progression of HF } \\
\text { phenotype, altered } \\
\text { leptin signaling }\end{array}$ & $22-26$ \\
\hline & & ob/ob mouse & $\begin{array}{l}\text { Reliable model of } \\
\text { T2D }\end{array}$ & $\begin{array}{l}\text { Time-dependent } \\
\text { progression of HF } \\
\text { phenotype, altered } \\
\text { leptin signaling }\end{array}$ & $22-26$ \\
\hline & \multirow[t]{3}{*}{ Type 1 diabeties } & Akita mouse & $\begin{array}{l}\text { Mimics time of T1D } \\
\text { development in } \\
\text { humans }\end{array}$ & $\begin{array}{l}\text { Time-dependent } \\
\text { progression of HF } \\
\text { phenotype }\end{array}$ & 27,28 \\
\hline & & STZ & $\begin{array}{l}\text { Reliable model of } \\
\text { T1D }\end{array}$ & $\begin{array}{l}\text { Toxicity to pancreas if } \\
\text { dosed to high, does } \\
\text { not model } \\
\text { autoimmune aspect } \\
\text { of the disease }\end{array}$ & $29-31$ \\
\hline & & OVE26 mouse & $\begin{array}{l}\text { Mimics acute onset } \\
\text { of T1D in children }\end{array}$ & $\begin{array}{l}\text { Time-dependent } \\
\text { progression of HF } \\
\text { phenotype }\end{array}$ & 32,33 \\
\hline & \multirow[t]{2}{*}{ Obesity } & High-fat diet & $\begin{array}{l}\text { Mimics metabolic } \\
\text { abnormalities } \\
\text { found in humans }\end{array}$ & $\begin{array}{l}\text { HF takes } 20 \text { weeks to } \\
\text { develop }\end{array}$ & $34-37$ \\
\hline & & $\begin{array}{l}\text { High-fat diet }+ \\
\text { physiological stress }\end{array}$ & $\begin{array}{l}\text { Mimics metabolic } \\
\text { abnormalities } \\
\text { found in humans }\end{array}$ & $\begin{array}{l}\text { HF takes } 16 \text { weeks to } \\
\text { develop }\end{array}$ & 38 \\
\hline & Aging & SAMP/SAMPR mice & $\begin{array}{l}\text { Allows for studying } \\
\text { age-induced } \\
\text { HFpEF on a } \\
\text { shorter time line }\end{array}$ & $\begin{array}{l}\text { May have non- } \\
\text { specific effects on } \\
\text { the mouse during } \\
\text { aging }\end{array}$ & 39,40 \\
\hline \multirow[t]{2}{*}{ HFrEF } & \multirow[t]{2}{*}{ LV pressure overload } & TAC & $\begin{array}{l}\text { Reliable model of } \\
\text { hypertrophy }\end{array}$ & $\begin{array}{l}\text { Technically } \\
\text { demanding surgery }\end{array}$ & $41-44$ \\
\hline & & $\begin{array}{l}\text { TAC double-loop } \\
\text { technique }\end{array}$ & $\begin{array}{l}\text { Easier surgery } \\
\text { where degree of } \\
\text { hypertension is } \\
\text { more } \\
\text { reproducible }\end{array}$ & & 45 \\
\hline
\end{tabular}

(table continues) 
Table 1 (continued)

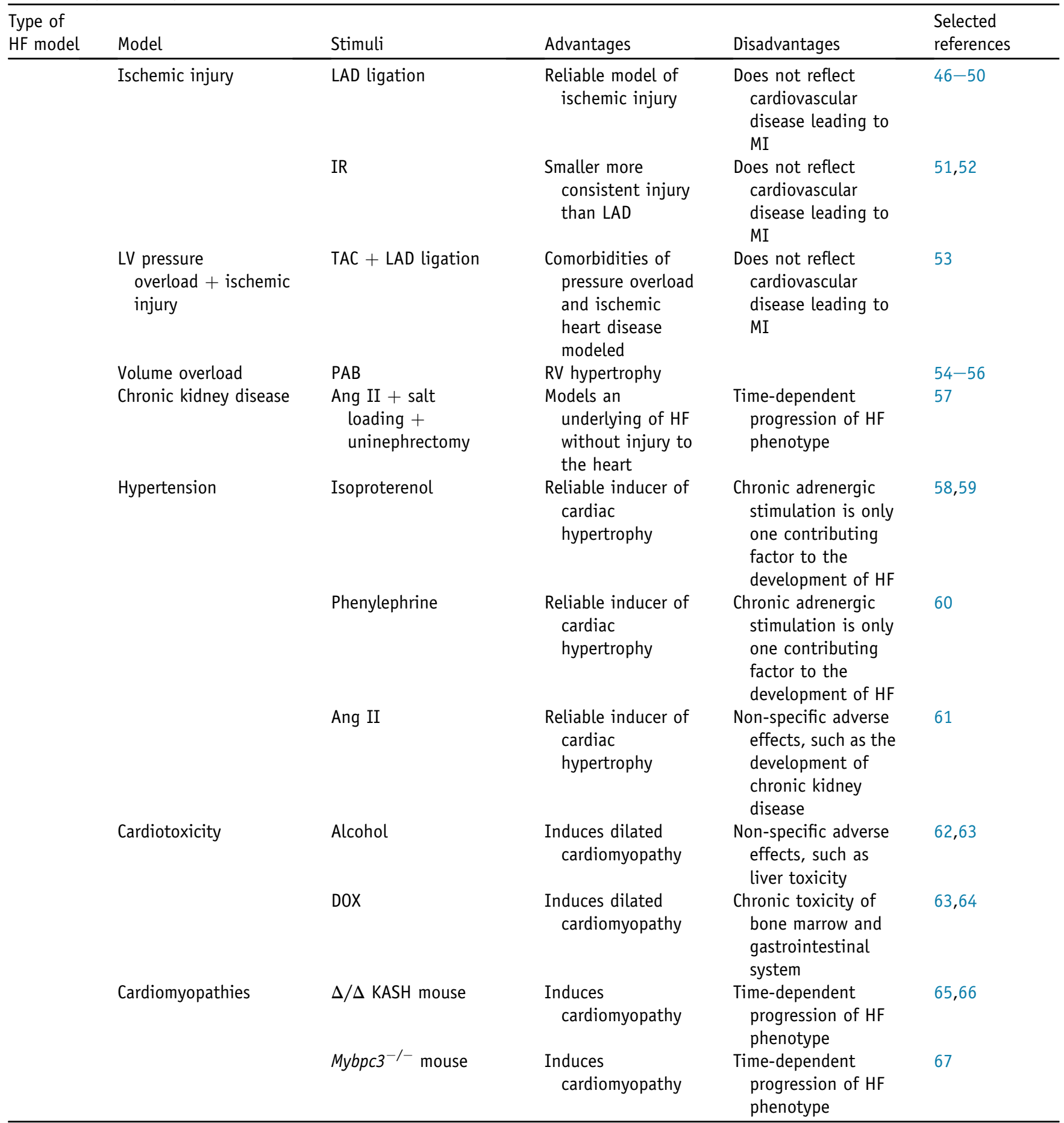

Ang II, angiotensin II; DOCA, deoxycorticosterone acetate; DOX, doxorubicin; HF, heart failure; HFpEF, HF with preserved ejection fraction; HFrEF, HF with reduced ejection fraction; IR, ischemia/reperfusion; $L A D$, left anterior descending artery; LV, left ventricle; MI, myocardial infarction; $P A B$, pulmonary aortic banding; RV, right ventricular; SAMP, senescence prone; SAMPR, senescence resistant; STZ, streptozotocin; T1D, type 1 diabetes; T2D, type 2 diabetes; TAC, transverse aortic constriction.

as they result in age-dependent diastolic dysfunction in the absence of systolic dysfunction. In addition, there is an increase in pathologic fibrosis and the production of the profibrotic cytokines transforming growth factor- $\beta$ and connective tissue growth factor. ${ }^{40}$

\section{Advantages and Disadvantages of HFpEF Models}

HFpEF results from systemic underlying conditions that cause diastolic dysfunction to develop over time with the progression of the principle disease. To study HFpEF, 
mouse models aim to accurately recapitulate the risk factors of HFpEF, which include hypertension, obesity, diabetes, and aging. In hypertension-induced HFpEF mouse models, DOCA and Ang II administration both cause systemic changes to the cardiovascular system with increased blood pressure through the renin-aldosterone pathways. This makes DOCA and Ang II advantageous models for looking at HFpEF progression because there is no direct insult on the heart. However, both DOCA and Ang II have effects on the kidneys, leading to CKD, which could cause additional changes to the heart outside the scope of just hypertension.

These potential off-target effects are additionally seen in the T2D models of $\mathrm{db} / \mathrm{db}$ and ob/ob mice. Altered leptin signaling in these mice is also seen in addition to changes in tyrosine kinase and immune signaling in humans with T2D. ${ }^{25,78}$ In addition, in both the ob/ob and $\mathrm{db} / \mathrm{db}$ models of $\mathrm{T} 2 \mathrm{D}$, there is a reverse lipid profile compared with humans, high high-density lipoprotein and low low-density lipoprotein, which results in high clearance of lipoprotein that keeps atherosclerosis from developing spontaneously, as seen in humans with T2D. ${ }^{81}$ Altered signaling in other tissues/organs is not an issue in T1D-induced HFpEF mouse models, as the pancreatic $\beta$-cells in the Akita, STZ, and OVE26 mice are destroyed. The advantages of using the Akita mice and OVE26 mice are that they develop T1D due to genetic mutations. The Akita mouse develops T1D at 5 to 6 weeks of age, which is equivalent to humans who developed T1D between 15 and 25 years of age and will survive with insulin treatment until HFpEF occurs. OVE26 mice develop T1D after the first week of life, making it a good model of childhood T1D. In addition, they can be aged for a year without insulin treatment, allowing them to be a model of T1D-induced HFpEF with untreated T1D. The advantage of using STZ toxin to induce the onset of T1D and HFpEF is that it can be given when the mice are at a specific age, allowing researchers to study T1D-induced HFpEF when T1D occurs at multiple ages. However, too high a dose of STZ has off-target effects and can cause toxicity outside of the pancreas because STZ is a potent alkylating agent. These effects include direct and indirect immunosuppressive effects through toxicity on lymphocytes and $\mathrm{B}$ cells, as well as toxicity to the kidney, liver, and brain. ${ }^{82}$

Obesity and aging models of HFpEF develop diastolic dysfunction over time without directly causing the initiation of any of the other precursors of HFpEF. This is advantageous because there is no direct insult to the mouse's system through the ablation of a particular cellular population or by injecting a toxin systemically. However, this means the mice could develop multiple risk factors for HFpEF, such as hypertension and diabetes, and the individual contribution of each risk factor to HFpEF may be hard to parse out, as each animal may not develop the same underlying conditions.

Additional spontaneously developed insults, such as myocardial infarction, in all models of HFpEF can cause further cardiovascular remodeling. In such instances, this can drive extracellular matrix deposition, LV wall thinning, and additional hypertrophy, resulting in systolic dysfunction and HFrEF (Figure 1). Therefore, it is suggested that echocardiographic analysis of all mice should be performed during HFpEF studies to monitor diastolic dysfunction and any potential systolic dysfunction occurring.

A key limitation of all the above preclinical HFpEF models is that they largely reflect a temporary stage of ejection fraction maintenance during the initial trajectory of the disease and ultimately lead to the HFrEF phenotype. A transition from HFpEF to HFrEF is not typical of all human etiologies. Thus, these animal models of HFpEF fail to accurately recapitulate all the HFpEF phenotypes observed in humans. Overall, the attempts to developing novel and relevant animal models of HFpEF have been disappointing. This has seriously hampered our mechanistic understanding of the fundamental biology of HFpEF. In humans, HFrEF cardiomyocytes are characterized as a systolic deficit, compromised contractile potential, with depleted $\mathrm{Ca}^{2+}$ reserves, whereas these characteristics are not featured in the HFpEF cardiomyocytes. Unfortunately, the current preclinical models of HFpEF have not yet facilitated the discovery of fundamentally different biology of cardiomyocytes or other cell types in the heart specific to HFpEF. The emergence of a patient-specific human-induced pluripotent stem cell-derived cardiomyocyte and fibroblast model system has brought new hope. Functional studies with HFpEF patient-derived human-induced pluripotent stem cell-induced cardiomyocytes or bioengineered microtissues from them have the potential to revolutionize the fundamental research of HFpEF biology, including the fact that bioengineered tissue patches from HFpEF patients can display a phenotype of relaxation defects and diastolic dysfunction, with maintained contractility ${ }^{83,84}$ However, as of now, the field of human-induced pluripotent stem cell-derived cardiomyocyte biology is facing challenges of relatively immature cardiomyocytes and difficulty in maintaining a differentiated phenotype for long-term studies. Therefore, although this model system has enormous potential, only time will tell if it can accurately mimic the HFpEF phenotype.

\section{Mouse Models of HFrEF}

The following sections discuss mouse models that routinely result in HFrEF (Table 1). Some of these models initially cause HFpEF, with the eventual development of systolic dysfunction indicative of HFrEF.

\section{Surgical Models of HFrEF}

\section{Pressure Overload}

Hypertension is the single most important risk factor for the development of HFrEF in the United States. ${ }^{85}$ To study 
HFrEF induced by chronic pressure overload of the LV, various surgical approaches have been developed to mimic the adaptations associated with hypertension in patients. Rockman et $\mathrm{al}^{54}$ first described the transverse aortic constriction (TAC) method, and this is currently the most prevalent method of studying LV pressure overload-induced HF. TAC causes an increase in LV afterload, resulting in concentric hypertrophy, interstitial fibrosis, and increasing LV stiffness, eventually leading to systolic failure. ${ }^{42,54,85}$ The severity of the TAC procedure is assessed by measurement of pulsed wave Doppler images of the aortic arch and comparing these with sham animals. ${ }^{43}$ The TAC model has allowed for the discovery of many underlying causes of $\mathrm{HF}$, including that $\mathrm{NOS3}^{-/-}$augments $\mathrm{LV}$ remodeling. ${ }^{44}$ However, the TAC procedure is not without its drawbacks, as it is highly operator dependent, has poor reproducibility, and is technically demanding, which can lead to variable degrees of aortic constriction. The hypertrophic response to TAC and the progression to HF depends on the sex, weight, age, and genetic background of the mice. This is exemplified by C57BL/6J mice developing HFrEF, with a similar expression pattern to human dilated cardiomyopathy, more readily post-TAC than $129 / \mathrm{Sv}$ mice. ${ }^{43}$ In addition, the range of mortality of TAC varies between studies as much as $6 \%$ to $45 \%$ when a large TAC is induced. ${ }^{43,86,87}$

More recently, a modified TAC technique, the double loop-clip technique, was developed to decrease variability during the surgical procedure. Merino et $\mathrm{al}^{45}$ measured the mid aortic arch's luminal diameter during presurgery echocardiography to calculate the interknot span of the suture for the modified double loop-clip technique. This allowed for the customization of the constriction to the mouse somatometry. This new procedure results in a far more accurate, reproducible stenosis that decreases mouse mortality and increases the homogeneity of structural and molecular features after aortic constriction. ${ }^{45}$

\section{Ischemic Injury}

Coronary artery ligation is the most common mouse model used to mimic myocardial infarction (MI). ${ }^{46}$ Ligation of the left anterior descending artery results in HF, with HFrEF developing by 6 weeks after infarction. Myocyte death and extracellular matrix deposition leading to a collagenous scar can be assessed by Evans Blue and 2,3/5-triphenyltetrzolium chloride double staining, where the typical infarct area is between $50 \%$ and $60 \%$ of the total LV wall area. ${ }^{42,47}$ This results in thinning and dilation of the infarcted area, causing reactive hypertrophy and fibrosis in the nonaffected myocardium and eventual LV dilation and impaired systolic function. ${ }^{48,49}$ In addition, PH develops in these mice, with severity proportional to the size of the infarct. ${ }^{50}$ Although coronary artery ligation is a reliable model to induce tissue damage that leads to HFrEF, it does not reflect the development of HF in patients, as the underlying factors that cause MI in humans-coronary artery disease, atherosclerosis, thrombus formation, and hypertension-do not exist in this model.

Ischemia/reperfusion (IR) injury during MI is a major cause of morbidity and mortality of patients with $\mathrm{HF}^{88} \mathrm{IR}$ injury in the heart results in cardiac remodeling and fibrosis, resulting in HFrEF. In mice, IR injury is simulated by temporarily occluding the left anterior descending artery to produce transient ischemia to the $\mathrm{LV}{ }^{51}$ This procedure results in a smaller injury than is achieved by coronary artery ligation. ${ }^{52}$ Furthermore, the IR mouse model closely parallels the clinical scenario where reperfusion of the occluded vessel occurs during coronary angiography after an acute MI.

\section{Other Surgical Models}

Increasing clinical evidence has shown that ischemic heart disease and accompanying hypertension result in additional risk factors for developing HFrEF. ${ }^{80}$ Previously studied in dogs and rats, a mouse model has been developed where a moderate TAC is performed on mice followed by a small MI (myocardial injury is $<25 \%$ of infarct size). ${ }^{53}$ In this model, LV remodeling after MI is exaggerated because of increased wall stresses from the induced hypertension. This leads to progressive LV dilation, interstitial fibrosis, and an increase in LV mass 28 days following the procedures. This model more accurately models the comorbidities of arterial hypertension and ischemic heart disease than TAC or MI alone.

Pulmonary aortic banding in mice mimics $\mathrm{PH}$ and pulmonary stenosis in humans and is used as a model of right ventricular hypertrophy and HF in mice. ${ }^{54}$ Pulmonary aortic banding results in concentric hypertrophy, increased heart weight, and myocardial fibrosis 8 weeks after injury. ${ }^{55}$ The severity of the pulmonary aortic banding correlates with the progression of cardiac dysfunction and mortality. ${ }^{56}$

CKD is often a common underlying cause of HFrEF because of increased hypertension and other cardiopulmonary dysregulation associated with impaired kidney function. In a study of the Acute Decompensated Heart Failure National Registry, $60 \%$ of the patients studied had CKD. ${ }^{89}$ Considering these data, CKD mouse models are being used to study the effects of CKD on myocardial dysfunction during HF. Common models of CKD, such as Ang II administration, salt loading, and uninephrectomy, result in HFrEF with systolic dysfunction, pulmonary congestion, cardiomyocyte hypertrophy, and an increase in fibrosis 6 weeks after injury. ${ }^{57}$

\section{Pharmacologic Models of HFrEF}

Toxin-induced HF models have been increasingly used to study the underlying causes of HFrEF, including chemotoxicity, hypertension, renal injury, and liver injury. ${ }^{58,62,64}$ These models aim to induce a systemic injury to the mouse instead of specifically targeting the cardiovascular system. This section will summarize the mechanisms of 
action, cardiovascular effects, and disadvantages associated with several commonly used toxin-induced models of HF.

Chronic adrenergic stimulation is a hallmark of chronic HF. ${ }^{90}$ To isolate this stimulation, isoproterenol (ISO), a nonselective $\beta$-adrenergic agonist, is administered to mice using an implanted osmotic pump or continuous injections. Echocardiography illustrates that cardiac hypertrophy, dilation, and ventricular dysfunction develop after 3 weeks of continuous ISO administration. ${ }^{58}$ ISO additionally causes cardiomyocyte apoptosis, leading to a decreased ability of the ventricle to contract. ${ }^{58}$ Mice of different genetic backgrounds have varying increases in LV mass, hypertrophy, and dilation, as well as variable decreases in ejection fraction, suggesting that dosing of ISO must be matched to the genetic background of the mice being used. ${ }^{59}$

Phenylephrine is an $\alpha$-adrenergic agonist that causes vasoconstriction, resulting in an increase in afterload and a decrease in ventricular function. When given in mouse models, phenylephrine causes myocardial hypertrophy of the LV, increased LV weight, systolic dysfunction, and increased expression of HF markers atrial natriuretic peptide and brain natriuretic peptide. ${ }^{60}$ When Ang II, another potent vasoconstrictive hormone, is given as a s.c. infusion over 14 days, mice develop hypertension, vascular inflammation, and fibrosis. ${ }^{61}$ Phenylephrine and Ang II have also been given in conjunction to increase total vasoconstriction in the cardiovascular system and exacerbate HFrEF. The main drawback of adrenergic and Ang II-induced HFrEF is that they only recapitulate one component of the disease.

Alcohol is one of the most commonly abused substances in the United States. Although its effects on liver injury have been studied in-depth, there is a smaller amount of research looking at the secondary development of alcohol-induced cardiotoxicity. Injection of ethanol into mice has been developed as a model of alcohol-induced cardiac disease. ${ }^{91}$ This method results in reduced cardiac contractility, enlarged cardiomyocytes, myocyte apoptosis, and mitochondrial damage. These were also all increased with overexpression of alcohol dehydrogenase transgene in mice with a decreased LV diastolic pressure. ${ }^{62}$

Doxorubicin (DOX) is a widely used chemotherapeutic agent used as a treatment for many cancers (eg, breast, ovary, thyroid, and bone tumors)..$^{92}$ Dose-dependent DOXinduced cardiotoxicity has been noted in these patients a short time after treatment. ${ }^{93}$ Mice differing in sex, age, or genetic background react differently to DOX administration, but all experienced some degree of cardiac injury that worsened over time, even after DOX treatment was halted. ${ }^{63,64}$ Chronic DOX toxicity in these mice presents with interstitial fibrosis, pervasive fibril atrophy and disorganization, collagen remodeling, and dense infiltration of macrophages and myofibroblasts most commonly observed in the atria as atrial lesions. ${ }^{64}$ These mice additionally experience toxic adverse effects in their bone marrow and gastrointestinal systems, making this model less than ideal for the investigation of immunologic impacts on HF.

\section{Genetic Models}

Transgenic mouse models have become the norm when investigating the impact of specific genes on cellular and molecular pathways during HF. The two most popular methods to generate whole-body gene deletions and conditional knockouts are the Cre/loxP and Flippase/FRTmediated recombination methods. These methods combine Cre/loxP or Flippase/FRT with a specific promoter (eg, periostin) that is unique to a target cardiac cell type. ${ }^{94}$ These models have been useful in studying the various underlying causes of dilated cardiomyopathy, which can lead to HFrEF. Dilated cardiomyopathy is the leading cause of HF and has been linked to mutations in $>40$ different genes. These mutated genes can be grouped broadly into four categories: nuclear envelope, sarcomere, cytoskeletal, and other proteins. ${ }^{95}$ This section will discuss an example of commonly used genetic models of dilated and hypertrophic cardiomyopathy.

The LINC complex is composed of proteins that interact with the nuclear envelope that form the physical link between the cytoskeleton and the interior of the nucleus. Many diseases have been associated with mutation in LINC complex proteins, including nesprin-1 and nesprin-2, which lead to X-linked Emery-Dreifuss muscular dystrophy and cardiomyopathy. ${ }^{96} \Delta / \Delta$ KASH mice are homozygous for a nesprin-1 allele but lack the KASH domain, and instead have an alternative sequence that is not homologous to any known protein domain. ${ }^{65}$ At 52 weeks of age, $\Delta / \Delta \mathrm{KASH}$ mice exhibited longer $\mathrm{P}$ duration, an elongated QRS duration, and an increased atrial effective refectory period, which indicate the development of conduction defects. ${ }^{66} \mathrm{In}$ addition, fractional shortening at 52 weeks is decreased, indicating HFrEF. This mimics systolic dysfunction seen in patients with dilated cardiomyopathy with conduction system defects.

Another genetic model interferes with myosin-binding protein-C (MYBPC), a thick filament accessory protein that is present in sarcomeres. Mutations in this protein result in $20 \%$ to $30 \%$ of all mutations in familial hypertrophic cardiomyopathy. ${ }^{67} \mathrm{Mybpc}^{-1-}$ mice exhibited significant cardiac hypertrophy with interstitial fibrosis at 8 weeks of age, along with systolic dysfunction. Impaired contractile function was also exhibited in these mice, as myocytes had increased $\mathrm{Ca}^{2+}$ sensitivity of tension. ${ }^{67}$

\section{Advantages and Disadvantages of HFrEF Models}

Mouse models of HFrEF provide several advantages and disadvantages to researchers. Surgical models, such as TAC and MI, are technically demanding, can be hard to reproduce, and have a large degree in variability in the injury that occurs. ${ }^{97}$ However, with new alteration to past techniques, such as the double loop-clip technique to the TAC surgery, the reproducibility of consistent injury severity is increased. Surgical models of HFrEF work by generating an acute 
injury to the heart either directly, as in MI and IR, or indirectly, as in TAC. As a result, the systemic factors associated with chronic disease leading to HFrEF are not recapitulated in these surgical models. However, these mouse models do allow for study of fibrotic and hypertrophic remodeling that are a direct response to the acute cardiac injury. These models have been used in studies such as those involving Xinji'erkang, a medication used clinically to treat coronary heart disease and myocarditis, to show Xinji'erkang has a cardioprotective effect following MI in mice by reducing oxidative stress and improving endothelial dysfunction. $^{98}$

DOX, alcohol, Ang II, and toxin-induced models of HFrEF, cause a systemic injury that leads to the development of HFrEF. These models are advantageous in that they cause the mice to develop one of the underlying conditions that lead to HF (namely, hypertensive heart disease). They allow for the accurate study of disease progression and are more representative of the development of HFrEF in humans. This was demonstrated recently, where blocking toll-like receptor 2 was identified as a potential therapeutic strategy for the treatment of DOX-induced dilated cardiomyopathy. Toll-like receptor 2 isotype-matched IgG antibody administration resulted in reduced mortality, decreased cardiac dysfunction by $13 \%$, and diminished cardiac fibrosis. ${ }^{63}$ Although systemic injury allows for targeting of the underlying cause of HFrEF, this introduces many variables into these studies that can result in confounding data. ISO and phenylephrine are more specific and act as adrenergic agonists, limiting some of the offtarget cardiovascular injuries while allowing for the study of HF progression.

With an increase in genetic testing and knowledge of genetic mutations that result in HF, genetic mouse models are an ideal way to study these diseases and their resulting pathologies. By generating models of known cardiomyopathies due to genetic mutations, such as nesprin-1 and MYBPC, researchers can more easily explore altered protein expression and molecular pathways to discover potential new mechanisms of action and treatment strategies. In addition, Cre/loxP and Flippase/FRT systems can be used to study the knockout or overexpression of proteins in specific cell types. In conjunction with surgical or toxin-induced models of HFrEF, the Cre/loxP system has allowed for the study of cardiac fibroblasts and the immune system in fibrotic remodeling during HFrEF after MI. The Cre/loxP model has been used to selectively knock out glycogen synthase kinase- $3 \beta$ in cardiac fibroblasts, resulting in cardiac fibroblasts adopting a myofibroblast phenotype and mice developing LV dysfunction and fibrosis after MI. ${ }^{99}$

Although mouse models have allowed for advancement in the study of HF, they have limitations. Mice are inbred, resulting in little heterogeneity, which does not reflect the vast genetic diversity seen in humans. In addition, most mouse studies of $\mathrm{HF}$ are performed in male adolescent mice. Because HF disproportionately affects elderly individuals, changes in the cardiovascular system due to aging are not recapitulated in these models.

\section{Summary and Conclusion}

In summary, the mouse models of HFrEF are well established and characterized; however, the ideal HFpEF animal model is yet to be developed and optimized. Nonetheless, mouse models of HFpEF and HFrEF are effective tools for researchers investigating novel pathologies and therapies in HF. These models mimic various aspects of the underlying conditions that cause HFpEF and HFrEF to help decipher numerous underlying contributing mechanisms of the disease. Although several limitations of these mouse models warrant the interpretation of the results of the studies performed with caution, mouse models of HFpEF and HFrEF have advanced the understanding of the pathogenesis of HF. On the basis of advancements in gene editing, numerous transgenic mouse models will further advance our knowledge in this area in the near future. These models in combination with surgical and toxin-induced models of $\mathrm{HFpEF}$ and HFrEF will continue to facilitate the identification of new targets and development of novel treatment strategies for HFpEF and HFrEF patients.

\section{References}

1. Masoudi FA, Havranek EP, Smith G, Fish RH, Steiner JF, Ordin DL, Krumholz HM: Gender, age, and heart failure with preserved left ventricular systolic function. J Am Coll Cardiol 2003, 41:217-223

2. Roger VL, Weston SA, Redfield MM, Hellermann-Homan JP, Killian J, Yawn BP, Jacobsen SJ: Trends in heart failure incidence and survival in a community-based population. JAMA 2004, 292:344-350

3. Mozaffarian D, Benjamin EJ, Go AS, Arnett DK, Blaha MJ, Cushman M, et al: Executive summary: heart disease and stroke statistics-2016 update a report from the American Heart Association. Circulation 2016, 133:447-454

4. Hawkins NM, Petrie MC, Jhund PS, Chalmers GW, Dunn FG, McMurray JJV: Heart failure and chronic obstructive pulmonary disease: diagnostic pitfalls and epidemiology. Eur J Heart Fail 2009, 11:130-139

5. Suthahar N, Meijers WC, Silljé HHW, de Boer RA: From inflammation to fibrosis - molecular and cellular mechanisms of myocardial tissue remodelling and perspectives on differential treatment opportunities. Curr Heart Fail Rep 2017, 14:235-250

6. Chen W, Frangogiannis NG: Fibroblasts in post-infarction inflammation and cardiac repair. Biochim Biophys Acta 2012, 1833: 945-953

7. Lamb HJ, Beyerbacht HP, Van Der Laarse A, Stoel BC, Doornbos J, Van Der Wall EE, de Roos A: Diastolic dysfunction in hypertensive heart disease is associated with altered myocardial metabolism. Circulation 1999, 99:2261-2267

8. Simmonds SJ, Cuijpers I, Heymans S, Jones EAV: Cellular and molecular differences between HFpEF and HFrEF: a step ahead in an improved pathological understanding. Cells 2020, 9:242

9. Lips DJ, Dewindt LJ, Van Kraaij DJW, Doevendans PA: Molecular determinants of myocardial hypertrophy and failure: alternative pathways for beneficial and maladaptive hypertrophy. Eur Heart J 2003, 24:883-896

10. Chugh SS, Reinier K, Teodorescu C, Evanado A, Kehr E, Al Samara M, Mariani R, Gunson K, Jui J: Epidemiology of sudden 
cardiac death: clinical and research implications. Prog Cardiovasc Dis 2008, 51:213-228

11. Hogg K, Swedberg K, McMurray J: Heart failure with preserved left ventricular systolic function: epidemiology, clinical characteristics, and prognosis. J Am Coll Cardiol 2004, 43:317-327

12. Borlaung BA, Redfield MM: Diastolic and systolic heart failure are distinct phenotypes of the heart failure syndrome. Circulation 2011, 123:2006-2013

13. Palazzuoli A, Ruocco G, Beltrami M, Nuti R, Cleland JG: Combined use of lung ultrasound, B-type natriuretic peptide, and echocardiography for outcome prediction in patients with acute HFrEF and HFpEF. Clin Res Cardiol 2018, 107:586-596

14. Uhl EW, Warner NJ: Mouse models as predictors of human responses: evolutionary medicine. Curr Pathobiol Rep 2015, 3: 219-223

15. Riehle C, Bauersachs J: Of mice and men: models and mechanisms of diabetic cardiomyopathy. Basic Res Cardiol 2019, 114:2

16. Hartner A, Cordasic N, Klanke B, Veelken R, Hilgers KF: Strain differences in the development of hypertension and glomerular lesions induced by deoxycorticosterone acetate salt in mice. Nephrol Dial Transplant 2003, 18:1999-2004

17. Karatas A, Hegner B, De Windt LJ, Luft FC, Schubert C, Gross V, Akashi YJ, Gürgen D, Kintscher U, Da Costa Goncalves AC, RegitzZagrosek V, Dragun D: Deoxycorticosterone acetate-salt mice exhibit blood pressure-independent sexual dimorphism. Hypertension 2008, $51: 1177-1183$

18. Westermann D, Becher PM, Lindner D, Savvatis K, Xia Y, Fröhlich M, Hoffmann S, Schultheiss HP, Tschöpe C: Selective PDE5A inhibition with sildenafil rescues left ventricular dysfunction, inflammatory immune response and cardiac remodeling in angiotensin ii-induced heart failure in vivo. Basic Res Cardiol 2012, 107: 308

19. Kirchhoff F, Krebs C, Abdulhag UN, Meyer-Schwesinger C, Maas R, Helmchen U, Hilgers KF, Wolf G, Stahl RAK, Wenzel U: Rapid development of severe end-organ damage in C57BL/6 mice by combining DOCA salt and angiotensin II. Kidney Int 2008, 73: 643-650

20. Mohammed-Ali Z, Cruz GL, Lu C, Carlisle RE, Werner KE, Ask K, Dickhout JG: Development of a model of chronic kidney disease in the C57BL/6 mouse with properties of progressive human CKD. Biomed Res Int 2015, 2015:172302

21. Meng Q, Lai YC, Kelly NJ, Bueno M, Baust JJ, Bachman TN, Goncharov D, Vanderpool RR, Radder JE, Hu J, Goncharova E, Morris AM, Mora AL, Shapiro SD, Gladwin MT: Development of a mouse model of metabolic syndrome, pulmonary hypertension, and heart failure with preserved ejection fraction. Am J Respir Cell Mol Biol 2017, 56:497-505

22. Semeniuk LM, Kryski AJ, Severson DL: Echocardiographic assessment of cardiac function in diabetic $\mathrm{db} / \mathrm{db}$ and transgenic db/db-hGLUT4 mice. Am J Physiol Heart Circ Physiol 2002, 283: 976-982

23. Christoffersen C, Bollano E, Lindegaard MLS, Bartels ED, Goetze JP, Andersen CB, Nielsen LB: Cardiac lipid accumulation associated with diastolic dysfunction in obese mice. Endocrinology 2003, 144:3483-3490

24. Stuckey DJ, Carr CA, Tyler DJ, Aasum E, Clarke K: Novel MRI method to detect altered left ventricular ejection and filling patterns in rodent models of disease. Magn Reson Med 2008, 60:582-587

25. Senador D, Kanakamedala K, Irigoyen MC, Morris M, Elased KM: Cardiovascular and autonomic phenotype of $\mathrm{db} / \mathrm{db}$ diabetic mice. Exp Physiol 2009, 94:648-658

26. Kashyap SR, DeFronzo RA: The insulin resistance syndrome: physiological considerations. Diab Vasc Dis Res 2007, 4:13-19

27. Bugger H, Abel ED: Molecular mechanisms for myocardial mitochondrial dysfunction in the metabolic syndrome. Clin Sci 2008, 114: 195-210
28. Lu Z, Jiang YP, Xu XH, Ballou LM, Cohen IS, Lin RZ: Decreased Ltype $\mathrm{Ca} 2+$ current in cardiac myocytes of type 1 diabetic akita mice due to reduced phosphatidylinositol 3-kinase signaling. Diabetes 2007, 56:2780-2789

29. Wang Z, Gleichmann H: GLUT2 in pancreatic islets: crucial target molecule in diabetes induced with multiple low doses of streptozotocin in mice. Diabetes 1998, 47:50-56

30. Kajstura J, Fiordaliso F, Andreoli AM, Li B, Chimenti S, Medow MS, Limana F, Nadal-Ginard B, Leri A, Anversa P: IGF-1 overexpression inhibits the development of diabetic cardiomyopathy and angiotensin II-mediated oxidative stress. Diabetes 2001, 50: $1414-1424$

31. Lacombe VA, Viatchenko-Karpinski S, Terentyev D, Sridhar A, Emani S, Bonagura JD, Feldman DS, Györke S, Carnes CA: Mechanisms of impaired calcium handling underlying subclinical diastolic dysfunction in diabetes. Am J Physiol Regul Integr Comp Physiol 2007, 293:1787-1797

32. Epstein PN, Overbeek PA, Means AR: Calmodulin-induced earlyonset diabetes in transgenic mice. Cell 1989, 58:1067-1073

33. Qian LB, Jiang SZ, Tang XQ, Zhang J, Liang YQ, Yu HT, Chen J, Xu Z, Liu RM, Keller BB, Ji HL, Cai L: Exacerbation of diabetic cardiac hypertrophy in OVE26 mice by angiotensin II is associated with JNK/c-Jun/miR-221-mediated autophagy inhibition. Oncotarget 2017, 8:106661-106671

34. Wang CY, Liao JK: A mouse model of diet-induced obesity and insulin resistance. Methods Mol Biol 2012, 821:421-433

35. Wright RJ, Frier BM, Deary IJ: Effects of acute insulin-induced hypoglycemia on spatial abilities in adults with type 1 diabetes. Diabetes Care 2009, 32:1503-1506

36. Chiang SH, Harrington WW, Luo G, Milliken NO, Ulrich JC, Chen J, Rajpal DK, Qian Y, Carpenter T, Murray R, Geske RS, Stimpson SA, Kramer HF, Haffner CD, Becherer JD, Preugschat F, Billin AN: Genetic ablation of CD38 protects against western diet-induced exercise intolerance and metabolic inflexibility. PLoS One 2015, 10: e0134927

37. Cox LS, Mattison JA: Increasing longevity through caloric restriction or rapamycin feeding in mammals: common mechanisms for common outcomes? Aging Cell 2009, 8:607-613

38. Agrimi J, Spalletti C, Baroni C, Keceli G, Zhu G, Caragnano A, Matteucci M, Chelko S, Ramirez-Correa GA, Bedja D, Casieri V, Lascio NDi, Scalco A, Beltrami AP, Paolocci N, Caleo M, Lionetti V: Obese mice exposed to psychosocial stress display cardiac and hippocampal dysfunction associated with local brain-derived neurotrophic factor depletion. EBioMedicine 2019, 47:384-401

39. Takeda T, Matsushita T, Kurozumi M, Takemura K, Higuchi K, Hosokawa M: Pathobiology of the senescence-accelerated mouse (SAM). Exp Gerontol 1997, 32:117-127

40. Reed AL, Tanaka A, Sorescu D, Liu H, Jeong E-M, Sturdy M, Walp ER, Dudley SC, Sutliff RL, Sutliff RL: Diastolic dysfunction is associated with cardiac fibrosis in the senescence-accelerated mouse. Am J Physiol Heart Circ Physiol 2011, 301:H824-H831

41. Rockman HA, Ross RS, Harris AN, Knowlton KU, Steinhelpert M, Fieldt LJ, Ross JJ, Chien KR: Segregation of atrial-specific and inducible expression of an atrial natriuretic factor transgene in an in vivo murine model of cardiac hypertrophy. Proc Natl Acad Sci U S A $1991,88: 8277-8281$

42. Mustonen E, Leskinen H, Aro J, Luodonpää M, Vuolteenaho O, Ruskoaho H, Rysä J: Metoprolol treatment lowers thrombospondin-4 expression in rats with myocardial infarction and left ventricular hypertrophy. Basic Clin Pharmacol Toxicol 2010, 107:709-717

43. Mohammed SF, Storlie JR, Oehler EA, Bowen LA, Korinek J, Lam CSP, Simari RD, Burnett JC, Redfield MM: Variable phenotype in murine transverse aortic constriction. Cardiovasc Pathol 2012, 21: 188-198

44. Ichinose F, Bloch KD, Wu JC, Hataishi R, Aretz HT, Picard MH, Scherrer-Crosbie M: Pressure overload-induced LV hypertrophy and 
dysfunction in mice are exacerbated by congenital NOS3 deficiency. Am J Physiol Heart Circ Physiol 2004, 286:H1070-H1075

45. Merino D, Gil A, Gómez J, Ruiz L, Llano M, García R, Hurlé MA, Nistal JF: Experimental modelling of cardiac pressure overload hypertrophy: modified technique for precise, reproducible, safe and easy aortic arch banding-debanding in mice. Sci Rep 2018, 8:3167

46. Sawall S, Franke D, Kirchherr A, Beckendorf J, Kuntz J, Maier J, Kraupner A, Backs J, Briel A, Kachelrieß M: In vivo quantification of myocardial infarction in mice using micro-CT and a novel blood pool agent. Contrast Media Mol Imaging 2017, 2017:2617047

47. Van Craeyveld E, Jacobs F, Gordts SC, De Geest B: Low-density lipoprotein receptor gene transfer in hypercholesterolemic mice improves cardiac function after myocardial infarction. Gene Ther 2012, 19:860-871

48. Swynghedauw B: Molecular mechanisms of myocardial remodeling. Physiol Rev 1999, 79:215-262

49. Ertl G, Frantz S: Healing after myocardial infarction. Cardiovasc Res 2005, 66:22-32

50. Dayeh NR, Tardif JC, Shi Y, Tanguay M, Ledoux J, Dupuis J: Echocardiographic validation of pulmonary hypertension due to heart failure with reduced ejection fraction in mice. Sci Rep 2018, 8:1363

51. Xu Z, Alloush J, Beck E, Weisleder N: A murine model of myocardial ischemia-reperfusion injury through ligation of the left anterior descending artery. J Vis Exp 2014, 10:51329

52. Rai V, Sharma P, Agrawal S, Agrawal DK: Relevance of mouse models of cardiac fibrosis and hypertrophy in cardiac research. Mol Cell Biochem 2017, 424:123-145

53. Weinheimer CJ, Lai L, Kelly DP, Kovacs A: Novel mouse model of left ventricular pressure overload and infarction causing predictable ventricular remodelling and progression to heart failure. Clin Exp Pharmacol Physiol 2015, 42:33-40

54. Rockman HA, Ono S, Ross RS, Jones LR, Karimi M, Bhargava V, Ross J, Chien KR: Molecular and physiological alterations in murine ventricular dysfunction. Proc Natl Acad Sci U S A 1994, 91: 2694-2698

55. Wang Q, Chen K, Lin H, He M, Huang X, Zhu H, Liao Y: Induction of right ventricular failure by pulmonary artery constriction and evaluation of right ventricular function in mice. J Vis Exp 2019, 147:e59431

56. Urashima $\mathrm{T}$, Zhao $\mathrm{M}$, Wagner $\mathrm{R}$, Fajardo $\mathrm{G}$, Farahani $\mathrm{S}$, Quertermous T, Bernstein D: Molecular and physiological characterization of rv remodeling in a murine model of pulmonary stenosis. Am J Physiol Heart Circ Physiol 2008, 295:H1351-H1368

57. Tsukamoto Y, Mano T, Sakata Y, Ohtani T, Takeda Y, Tamaki S, Omori Y, Ikeya Y, Saito Y, Ishii R, Higashimori M, Kaneko M, Miwa T, Yamamoto K, Komuro I: A novel heart failure mice model of hypertensive heart disease by angiotensin ii infusion, nephrectomy, and salt loading. Am J Physiol Heart Circ Physiol 2013, 305: h1658-h1667

58. Chang SC, Ren S, Rau CD, Wang JJ: Isoproterenol-induced heart failure mouse model using osmotic pump implantation. Methods Mol Biol 2018, 1816:207-220

59. Rau CD, Wang J, Avetisyan R, Romay MC, Martin L, Ren S, Wang Y, Lusis AJ: Mapping genetic contributions to cardiac pathology induced by beta-adrenergic stimulation in mice. Circ Cardiovasc Genet 2015, 8:40-49

60. Peng H, Yang XP, Carretero OA, Nakagawa P, D'Ambrosio M, Leung P, Xu J, Peterson EL, González GE, Harding P, Rhaleb NE: Angiotensin II-induced dilated cardiomyopathy in Balb/c but not C57BL/6J mice. Exp Physiol 2011, 96:756-764

61. Pan X, Shao Y, Wu F, Wang Y, Xiong R, Zheng J, Tian H, Wang B, Wang Y, Zhang Y, Han Z, Qu A, Xu H, Lu A, Yang T, Li X, Xu A, Du J, Lin Z: FGF21 prevents angiotensin II-induced hypertension and vascular dysfunction by activation of ACE2/angiotensin-(1-7) axis in mice. Cell Metab 2018, 27:1323-1337.e5

62. Guo R, Ren J: Alcohol dehydrogenase accentuates ethanol-induced myocardial dysfunction and mitochondrial damage in mice: role of mitochondrial death pathway. PLoS One 2010, 5:e8757
63. Ma Y, Zhang X, Bao H, Mi S, Cai W, Yan H, Wang Q, Wang Z, Yan J, Fan G, Lindsey ML, Hu Z: Toll-like receptor (TLR) 2 and tlr4 differentially regulate doxorubicin induced cardiomyopathy in mice. PLoS One 2012, 7:e40763

64. Zeiss CJ, Gatti DM, Toro-Salazar O, Davis C, Lutz CM, Spinale F, Stearns T, Furtado MB, Churchill GA: Doxorubicin-induced cardiotoxicity in collaborative cross $(\mathrm{CC})$ mice recapitulates individual cardiotoxicity in humans. G3 (Bethesda) 2019, 9:2637-2646

65. Puckelwartz MJ, Kessler E, Zhang Y, Hodzic D, Randles KN, Morris G, JU Earley, Hadhazy M, Holaska JM, Mewborn SK, Pytel P, McNally EM: Disruption of nesprin-1 produces an emery dreifuss muscular dystrophy-like phenotype in mice. Hum Mol Genet 2009, 18:607-620

66. Puckelwartz MJ, Kessler EJ, Kim G, DeWitt MM, Zhang Y, Earley JU, Depreux FFS, Holaska J, Mewborn SK, Pytel P, McNally EM: Nesprin-1 mutations in human and murine cardiomyopathy. J Mol Cell Cardiol 2010, 48:600-608

67. Harris SP, Bartley CR, Hacker TA, McDonald KS, Douglas PS, Greaser ML, Powers PA, Moss RL: Hypertrophic cardiomyopathy in cardiac myosin binding protein-C knockout mice. Circ Res 2002, 90: 594-601

68. Kannan A, Janardhanan R: Hypertension as a risk factor for heart failure. Curr Hypertens Rep 2014, 16:447

69. Berenji K, Drazner MH, Rothermel BA, Hill JA: Does load-induced ventricular hypertrophy progress to systolic heart failure? Am J Physiol Heart Circ Physiol 2005, 289:8-16

70. Simonneau G, Robbins IM, Beghetti M, Channick RN, Delcroiz M, Denton CP, Elliott CG, Gaine SP, Gladwin MT, Jing ZC, Krowka MJ, Langleben D, Nakanishi N, Souza R: Updated clinical classification of pulmonary hypertension. J Am Coll Cardiol 2012, 54:S43-S54

71. Cappola TP, Felker GM, Kao WHL, Hare JM, Baughman KL, Kasper EK: Pulmonary hypertension and risk of death in cardiomyopathy: patients with myocarditis are at higher risk. Circulation 2002, 105:1663-1668

72. Delgado JF, Conde E, Sánchez V, López-Ríos F, GómezSánchez MA, Escribano P, Sotelo T, De La Cámara AG, Cortina J, De La Calzada CS: Pulmonary vascular remodeling in pulmonary hypertension due to chronic heart failure. Eur J Heart Fail 2005, 7: $1011-1016$

73. Leung CC, Moondra V, Catherwood E, Andrus BW: Prevalence and risk factors of pulmonary hypertension in patients with elevated pulmonary venous pressure and preserved ejection fraction. Am J Cardiol 2010, 106:284-286

74. Garcia MJ, McNamara PM, Gordon T, Kannell WB: Morbidity and mortality in diabetics in the framingham population: sixteen year follow up study. Diabetes 1974, 23:105-111

75. Cavaghan MK, Ehrmann DA, Polonsky KS: Interactions between insulin resistance and insulin secretion in the development of glucose intolerance. J Clin Invest 2000, 106:329-333

76. Hayden JM, Reaven PD: Cardiovascular disease in diabetes mellitus type 2: a potential role for novel cardiovascular risk factors. Curr Opin Lipidol 2000, 11:519-528

77. Buchanan J, Mazumder PK, Hu P, Chakrabarti G, Roberts MW, Ui JY, Cooksey RC, Litwin SE, Abel ED: Reduced cardiac efficiency and altered substrate metabolism precedes the onset of hyperglycemia and contractile dysfunction in two mouse models of insulin resistance and obesity. Endocrinology 2005, 146:5341-5349

78. Anstee QM, Goldin RD: Mouse models in non-alcoholic fatty liver disease and steatohepatitis research. Int J Exp Pathol 2006, 87: $1-16$

79. Liu M, Sun J, Cui J, Chen W, Guo H, Barbetti F, Arvan P: INS-gene mutations: from genetics and beta cell biology to clinical disease. Mol Aspects Med 2015, 42:3-18

80. Chen J, Dharmarajan K, Wang Y, Krumholz HM: National trends in heart failure hospitalization rates, 2001- 2009. J Am Coll Cardiol 2013, 61:1078-1088 
81. Clark TA, Pierce GN: Cardiovascular complications of non-insulin-dependent diabetes: the JCR:LA-cp rat. J Pharmacol Toxicol Methods 2000, 43:1-10

82. Muller YD, Golshayan D, Ehirchiou D, Wyss JC, Giovannoni L, Meier R, Serre-Beinier V, Yung GP, Morel P, Bühler LH, Seebach JD: Immunosuppressive effects of streptozotocin-induced diabetes result in absolute lymphopenia and a relative increase of $\mathrm{T}$ regulatory cells. Diabetes 2011, 60:2331-2340

83. Goldfracht I, Efraim Y, Shinnawi R, Kovalev E, Huber I, Gepstein A, Arbel G, Shaheen N, Tiburcy M, Zimmermann WH, Machluf M, Gepstein L: Engineered heart tissue models from hiPSC-derived cardiomyocytes and cardiac ECM for disease modeling and drug testing applications. Acta Biomater 2019, 92:145-159

84. Burridge PW, Li YF, Matsa E, Wu H, Ong S-G, Sharma A, Holmström A, Chang AC, Coronado MJ, Ebert AD, Knowles JW, Telli ML, Witteles RM, Blau HM, Bernstein D, Altman RB, Wu JC, Author NM: Human induced pluripotent stem cell-derived cardiomyocytes recapitulate the predilection of breast cancer patients to doxorubicin-induced cardiotoxicity HHS public access author manuscript. Nat Med 2016, 22:547-556

85. Gradman AH, Alfayoumi F: From left ventricular hypertrophy to congestive heart failure: management of hypertensive heart disease. Prog Cardiovasc Dis 2006, 48:326-341

86. Hu P, Zhang D, Swenson LA, Chakrabarti G, Abel ED, Litwin SE: Minimally invasive aortic banding in mice: effects of altered cardiomyocyte insulin signaling during pressure overload. Am J Physiol Heart Circ Physiol 2003, 285:H1261-H1269

87. deAlmeida AC, van Oort RJ, Wehrens XHT: Transverse aortic constriction in mice. J Vis Exp 2010, 38:1729

88. Go AS, Mozaffarian D, Roger VL, Benjamin EJ, Berry JD, Borden WB, et al: Heart disease and stroke statistics-2013 update. Circulation 2013, 127:e6-e245

89. Heywood JT, Fonarow GC, Costanzo MR, Mathur VS, Wigneswaran JR, Wynne J: High prevalence of renal dysfunction and its impact on outcome in 118,465 patients hospitalized with acute decompensated heart failure: a report from the ADHERE database. J Card Fail 2007, 13:422-430

90. Lymperopoulos A, Rengo G, Koch WJ: Adrenergic nervous system in heart failure: pathophysiology and therapy. Circ Res 2013, 113: 739-753

91. Jones WK: A murine model of alcoholic cardiomyopathy. Am J Pathol 2005, 167:301-304

92. Carter SK: Adriamycin: a review. J Natl Cancer Inst 1975, 55: 1267-1274

93. Bristow MR, Thompson PD, Martin RP, Mason JW, Billingham ME, Harrison DC: Early anthracycline cardiotoxicity. Am J Med 1978, 65: $823-832$

94. Kanisicak O, Khalil H, Ivey MJ, Karch J, Maliken BD, Correll RN, Brody MJ, Lin SCJ, Aronow BJ, Tallquist MD, Molkentin JD: Genetic lineage tracing defines myofibroblast origin and function in the injured heart. Nat Commun 2016, 7:12260

95. Dellefave L, McNally EM: The genetics of dilated cardiomyopathy. Curr Opin Cardiol 2010, 25:198-204

96. Crisp M, Liu Q, Roux K, Rattner JB, Shanahan C, Burke B, Stahl PD, Hodzic D: Coupling of the nucleus and cytoplasm: role of the LINC complex. J Cell Biol 2006, 172:41-53

97. Barrick CJ, Rojas M, Schoonhoven R, Smyth SS, Threadgill DW: Cardiac response to pressure overload in 129S1/SvImJ and C57BL/6J mice: temporal- and background-dependent development of concentric left ventricular hypertrophy. Am J Physiol Heart Circ Physiol 2007, 292:H2119-H2130

98. Hu J, Zhang Y-X, Wang L, Ding L, Huang G-Y, Cai G-W, Gao S: Protective effects of Xinji'erkang on myocardial infarction induced cardiac injury in mice. BMC Complement Altern Med $2017,17: 338$

99. Lal H, Ahmad F, Zhou J, Yu JE, Vagnozzi RJ, Guo Y, Yu D, Tsai EJ, Woodgett J, Gao E, Force T: Cardiac fibroblast GSK-3 $\beta$ regulates ventricular remodeling and dysfunction in ischemic heart. Circulation 2014, 130:419-430 